\title{
EFFECTS OF THICKNESS AND BACKGROUND COLOR ON THE TRANSLUCENCY OF CAD/CAM CERAMIC MATERIALS
}

\author{
AFNAN F. ALFOUZAN*, HANAN N. AL-OTAIBI*, "NAWAF LABBAN*, SARA MOHAMMAD AL TAWEEL*, \\ SHAHAD AL-TUWAIJRI**, ALMAHA S. ALGAZLAN***, ESAM A. TASHKANDI* \\ *Department of Prosthetic Dental Sciences, College of Dentistry, King Saud University, \\ Riyadh, Saudi Arabia \\ **Postgraduate, King Saud University/Demonstrator, Prosthodontics Division, Restorative Department, \\ Majmaah University, Saudi Arabia \\ ***Postgraduate, King Saud University/Demonstrator, Endodontic Division, Restorative Department, \\ Majmaah University, Saudi Arabia \\ "E-mail: nalabban@ksu.edu.sa
}

Submitted April 17, 2020; accepted June 8, 2020

\begin{abstract}
Keywords: Translucency, Ceramic, Color change, Contrast ratio, Hybrid ceramic
The aim of this study was to compare the translucency of different thicknesses of three different CAD/CAM ceramic materials (zirconia-reinforced lithium silicate (Suprinity), lithium disilicate (IPS e.max CAD), and hybrid ceramic (Enamic). A total of 180 specimens were prepared from each materials at different thicknesses $(0.4 \mathrm{~mm}, 0.5 \mathrm{~mm}, 1 \mathrm{~mm}, 1.5 \mathrm{~mm}$, and $2 \mathrm{~mm})$. A spectrophotometer was used to measure the translucency using a contrast ratio (CR) against white and black backgrounds for all the specimens. Data was analyzed using ANOVA, one-sample t-test, and post-hoc multiple comparison test at a significance level of $P \leq 0.05$. The $C R$ increased significantly when the material thickness increased for all specimens of each material type $(P \leq 0.05)$, except for the e.max material, as there was no significant difference between 0.4 and $0.5 \mathrm{~mm}$, and between 1.0 and $1.5 \mathrm{~mm}$. The differences between the materials became more apparent with the increase in thickness. In addition, when comparing the three types of material, zirconia-reinforced lithium silicate appeared to have the highest contrast ratios. The study provides knowledge about the translucency of the different thickness of the CAD/CAM dental restorative materials which could help to overcome the disadvantages of the translucency in certain clinical situations.
\end{abstract}

\section{INTRODUCTION}

Esthetics have always had a significant impact on dentistry. They have become a priority for most patients and a concern for many practitioners. This higher demand for better esthetics has led to the increased use of ceramic materials [1], which are known for their superior optical characteristics [2-4].

Translucency, the transmission of diffused light from a substrate, plays a major role in the final esthetic results of any fabricated prosthesis, providing it with a more natural appearance [2-6]. The translucency is affected by a variety of factors, including the type of material to be used, its crystalline structure, grain size, pigmentation, and defects. The material thickness also has an impact on the translucency: a thinner material gives a more translucent appearance than a thicker one. In addition, lighter cement shades allow more translucency than opaque shades. The translucency is also determined by the color of the core; the lighter the core, the higher the translucency. Furthermore, the finishing technique, as well as the amount of crystals in the core and its chemical composition also influences the translucency [7-13].
Zirconia crowns provided acceptable esthetic results. However, their translucency did not meet the practitioners' expectations, especially in esthetically demanding areas $[11,14]$. On the other hand, lithium disilicate (e.max) crowns showed better translucency than zirconia crowns, making them the most common type of crown used for anterior restorations, nowadays [11, 14]. However, this material is highly influenced by the color of the core (background) [14]. Therefore, using it to restore a tooth with discolored dentin, for example, might compromise the esthetic result.

A hybrid ceramic with a dual network composite structure (Vita Enamic ${ }^{\mathbb{B}}$ ), was introduced in 2013, making it the first material to have the positive properties of both composites and ceramics. The dominant ceramic is strengthened by a polymer network, which offers high strength, elasticity similar to dentin, high reliability, crack prevention, and accurate milling results.

In 2015, Vita introduced a material composed of zirconia-reinforced lithium silicate glass-ceramic (Vita Suprinity $\left.{ }^{\circledR}\right)$. It was claimed to have a better ability to mask the color of the core than e.max and zirconia crowns, while still exhibiting a translucent effect. According to the manufacturer, this material has numerous advantages, 
e.g., long-term reliability, high load capacity (and, thus, high clinical success), easy milling and polishing as well as excellent translucency, fluorescence and opalescence.

However, there is a paucity of information in published studies related to zirconia-reinforced lithium silicate and hybrid ceramics. Therefore, the aim of this study was to compare the translucency of zirconiareinforced lithium silicate, lithium disilicate, and hybrid ceramics against different background colors with different thicknesses. The null hypothesis tested was that there were no differences in translucency between the different thicknesses of zirconia-reinforced lithium silicate, lithium disilicate, and hybrid ceramics.

\section{EXPERIMENTAL}

Three different ceramic materials: zirconia-reinforced lithium silicate (Suprinity, VITA Zahnfabrik, Bad Säckingen, Germany), lithium disilicate (IPS e.max CAD, Ivoclar Vivadent AG, Schaan, Liechtenstein), and hybrid ceramic (Enamic, VITA Zahnfabrik, Bad Sackingen, Germany) were used in the present study. Disks of each material were sliced to five thicknesses $(0.4 \mathrm{~mm}$, $0.5 \mathrm{~mm}, 1 \mathrm{~mm}, 1.5 \mathrm{~mm}$, and $2 \mathrm{~mm}$ ), with 12 disks of each thickness totaling to 180 specimens. Zirconia-reinforced lithium silicate and lithium disilicate was fired in the furnace (Programat EP 3000 furnace, Ivoclar Vivadent) according to the manufacturer's recommendations.

\section{Specimen preparation}

A clear self-curing orthodontic resin (Orthoresin, DENTSPLY Limited, Weybridge, Surrey, England) was used to invest the blocks of ceramic material into a silicon mold (Deguform plus, DeguDent GmbH, Germany) to prepare the ceramic blocks for the slicing process. A precision diamond cutter (Isomet 2000 Precision Saw, Buehler, IL, USA) was then used to slice the ceramic blocks to the predetermined thickness. To minimize the movement of the specimens during the cutting process, a custom positioning jig, made of clear self-curing orthodontic resin (Orthoresin, DENTSPLY Limited, Surrey, England), was fabricated.

The speed of the diamond cutter was standardized to $1000 \mathrm{rpm}$, and the blade thickness $(0.6 \mathrm{~mm})$ was accounted for during the cutting process. To position the blade correctly and establish its parallelism to the specimen, an initial cut was made for each block. An LCD digital electronic gauge with a stainless-steel caliper ruler was used to ensure the appropriate thickness of the specimens.

\section{Translucency measurement}

The translucency of all the specimens were measured against black and white backgrounds using a spect- rophotometer (Color-Eye 7000A Spectrophotometer, Michigan, USA). The translucency was measured using the contrast ratio (CR) according to the following equation:

$$
\mathrm{CR}=Y b / Y w,
$$

where $Y b$ is the ratio of the light reflectance on the material on a black surface and $Y w$ is the reflectance on a white surface. In this ratio, unity accounts for opaque materials, and zero accounts for transparent materials. Each specimen had a total of six readings, three readings with a white background and three readings with a black background; then, the readings were averaged for that particular specimen.

\section{Statistical Analysis}

The data were analyzed using the Statistical Package for Social Sciences (v. 21, IBM SPSS Inc., Chicago, USA). A two-way analysis of variance (ANOVA) was used to evaluate the effects of the material types and thicknesses on the contrast ratio. In addition, a one-way ANOVA was used to evaluate the differences between the ceramic materials for each thickness and between the different thicknesses for the same material. The GamesHowell post-hoc multiple comparison test was used to compare the effects of the material types on the $\mathrm{CR}$ for different material thicknesses. A $P$-value of $\leq 0.05$ was considered statistically significant.

\section{RESULTS}

A descriptive analysis, including the means and standard deviations of the contrast ratios (CR) of all material types and thicknesses is shown in Table 1. For the smallest thicknesses $(0.4 \mathrm{~mm}$ and $0.5 \mathrm{~mm})$, Enamic

Table 1. Descriptive analysis for the CR of all thicknesses.

\begin{tabular}{cccc}
\hline $\begin{array}{c}\text { Thickness } \\
(\mathrm{mm})\end{array}$ & $\begin{array}{c}\text { Material } \\
\text { type }\end{array}$ & $\begin{array}{c}\text { Mean } \\
\text { CR }\end{array}$ & $\begin{array}{r}\text { Standard } \\
\text { deviation }\end{array}$ \\
\hline \multirow{4}{*}{0.4} & Suprinity & 0.68 & 0.027 \\
& Emax & 0.68 & 0.049 \\
& Enamic & 0.69 & 0.01 \\
\hline \multirow{3}{*}{0.5} & Suprinity & 0.72 & 0.026 \\
& Emax & 0.69 & 0.049 \\
& Enamic & 0.73 & $<0.00$ \\
\hline \multirow{3}{*}{1.0} & Suprinity & 0.82 & 0.024 \\
& Emax & 0.8 & 0.02 \\
& Enamic & 0.77 & 0.01 \\
\hline \multirow{3}{*}{1.5} & Suprinity & 0.88 & 0.02 \\
& Emax & 0.82 & 0.01 \\
& Enamic & 0.82 & 0.01 \\
\hline \multirow{3}{*}{2.0} & Suprinity & 0.92 & 0.01 \\
& Emax & 0.86 & $<0.00$ \\
& Enamic & 0.78 & 0.06 \\
\hline
\end{tabular}


had the highest contrast ratio when compared to the other two materials. On the contrary, Suprinity exhibited higher contrast ratios for the remaining larger thickness $(1,1.5$, and $2 \mathrm{~mm})$.

There were no significant differences in contrast ratios between the materials when evaluating the 0.4 - and $0.5-\mathrm{mm}$ thicknesses. In contrast, the differences were sig-

Table 2. Comparison of the effect of the material type on the $\mathrm{CR}$ for different material thicknesses.

\begin{tabular}{|c|c|c|c|c|}
\hline $\begin{array}{l}\text { Thickness } \\
\text { (mm) }\end{array}$ & \multicolumn{2}{|c|}{ Material type } & $\begin{array}{c}\text { Mean } \\
\text { difference }\end{array}$ & Significance \\
\hline \multirow{6}{*}{0.4} & \multirow{2}{*}{ Suprinity } & E-max & -0.00132 & 0.996 \\
\hline & & Enamic & -0.01232 & 0.432 \\
\hline & \multirow[b]{2}{*}{ E-max } & Suprinity & 0.00132 & 0.996 \\
\hline & & Enamic & -0.01100 & 0.756 \\
\hline & \multirow{2}{*}{ Enamic } & Suprinity & 0.01232 & 0.432 \\
\hline & & E-max & 0.01100 & 0.756 \\
\hline \multirow{6}{*}{0.5} & \multirow{2}{*}{ Suprinity } & E-max & 0.02880 & 0.207 \\
\hline & & Enamic & -0.00239 & 0.951 \\
\hline & \multirow{2}{*}{ E-max } & Suprinity & -0.02880 & 0.207 \\
\hline & & Enamic & -0.03119 & 0.123 \\
\hline & \multirow{2}{*}{ Enamic } & Suprinity & 0.00239 & 0.951 \\
\hline & & E-max & 0.03119 & 0.123 \\
\hline \multirow{6}{*}{1.0} & \multirow{2}{*}{ Suprinity } & E-max & 0.01889 & 0.183 \\
\hline & & Enamic & 0.04276 & $<0.000^{*}$ \\
\hline & \multirow{2}{*}{ E-max } & Suprinity & -0.01889 & 0.183 \\
\hline & & Enamic & 0.02386 & $0.047 *$ \\
\hline & \multirow{2}{*}{ Enamic } & Suprinity & -0.04276 & $<0.000^{*}$ \\
\hline & & E-max & -0.02386 & $0.047^{*}$ \\
\hline \multirow{6}{*}{1.5} & \multirow{2}{*}{ Suprinity } & E-max & 0.06727 & $<0.000^{*}$ \\
\hline & & Enamic & 0.06040 & $<0.000^{*}$ \\
\hline & \multirow{2}{*}{ E-max } & Suprinity & -0.06727 & $<0.000^{*}$ \\
\hline & & Enamic & -0.00687 & 0.349 \\
\hline & \multirow{2}{*}{ Enamic } & Suprinity & -0.06040 & $<0.000^{*}$ \\
\hline & & E-max & 0.00687 & 0.349 \\
\hline \multirow{6}{*}{2.0} & \multirow{2}{*}{ Suprinity } & E-max & 0.05202 & $<0.000^{*}$ \\
\hline & & Enamic & 0.04124 & $<0.000^{*}$ \\
\hline & \multirow{2}{*}{ E-max } & Suprinity & -0.05202 & $<0.000^{*}$ \\
\hline & & Enamic & -0.01078 & $0.033^{*}$ \\
\hline & \multirow{2}{*}{ Enamic } & Suprinity & -0.04124 & $<0.000^{*}$ \\
\hline & & E-max & 0.01078 & $0.033^{*}$ \\
\hline
\end{tabular}

* Statistically significant at $P \leq .05$. nificant between all the material types when examining the larger thicknesses $(1.0,1.5$, and $2 \mathrm{~mm})(P \leq 0.05)$, except the $1.0-\mathrm{mm}$ specimens between E-max and Suprinity. In addition, the CR was non-significant when comparing the Enamic and e.max materials of 1.5-mm (Table 2).

For all three materials, the contrast ratio increased with the thickness of the specimen. When a material's thickness was compared to the next larger thickness, a significant increase in the $\mathrm{CR}$ was observed. This was evident in all materials $(P \leq 0.05)$, except the e.max material, where there was no significant difference between the 0.4 and $0.5 \mathrm{~mm}$ disks, or the 1.0 and $1.5 \mathrm{~mm}$ disks.

The two-way ANOVA analysis of the independent factors, material type, and thickness, revealed that each factor had a significant effect on the contrast ratio $(P \leq 0.05)($ Tab. 3)

\section{DISCUSSION}

In recent years, several types of ceramic material with different combinations and properties have been introduced to the market. As esthetics become a more valid and important concern, the optical properties of a material, including its translucency, color of the core, and thickness, have become the sole focus of many publications [3, 4, 6, 8-10].

Lithium disilicate is considered to have high translucency when compared to other types of CAD/CAM materials of the same thickness [15]. This could be a disadvantage on occasions where the color of the core needs to be masked [15]. Enamic is the first hybrid dental ceramic known to combine the properties of both composites and ceramics. It mimics many of the properties of natural dentin, e.g., wear characteristics, flexural properties, and elasticity. Furthermore, it proved to be strong in thin sections, due to the interpenetrating polymer within the network [15-17]. Enamic also appeared to have variable translucency, depending on the selected translucency level [1].

Suprinity (zirconia-reinforced lithium silicate), one of the newly introduced materials machinable with the CAD/CAM technique, differs from previous materials by incorporating zirconia in its structure. It was found

Table 3. Two-way ANOVA for the effect of the material type and thickness on the contrast ratio.

\begin{tabular}{|c|c|c|c|c|c|}
\hline Source material & $\begin{array}{c}\text { Type III } \\
\text { sums of squares }\end{array}$ & $\mathrm{DF}$ & Mean square & F-value & Significance \\
\hline Type & 0.036 & 2 & 0.018 & 28.894 & $<0.000^{*}$ \\
\hline Thickness & 1.014 & 4 & 0.253 & 401.881 & $<0.000^{*}$ \\
\hline Type* thickness & 0.034 & 8 & 0.001 & 6.714 & $<0.000^{*}$ \\
\hline
\end{tabular}


to have better physical properties and color-masking abilities [18]. Also, this material is reported to exhibit higher mechanical properties than e.max [19].

Most ceramic materials using the $\mathrm{CAD} / \mathrm{CAM}$ technique can withstand a $0.4-\mathrm{mm}$ thickness for minimally invasive veneers and can reach up to a $2-\mathrm{mm}$ thickness for posterior crowns [20]. The thickness of the material is dictated by many factors, e.g., the type of tooth, choice of restorative treatment, color of the core, and the physical and mechanical properties of the material. It is well known that the thickness of the restoration has a significant effect on the translucency and color shade of the final prosthesis $[10,21]$.

A $0.4-\mathrm{mm}$ thickness was selected in this study, as it was the minimal thickness for Suprinity and e.max that could provide good esthetic results on teeth with minimal discoloration. It is the preparation thickness of choice in veneer cases with good acceptable core colors $[20,22,23]$. The use of $0.5-\mathrm{mm}$ thickness are similar to that of $0.4-\mathrm{mm}$ thickness where minimum preparation is required. The recommended thickness for cervical preparations of anterior crowns is usually $1 \mathrm{~mm}$ for all of the selected materials $[22,24]$. On the other hand, the tooth should be prepared with a 1.5 to $2-\mathrm{mm}$ depth, if it will receive a full-coverage restoration, whether it is on a posterior or anterior tooth, even if it is discolored [25].

Different methods have been described in the literature to measure the translucency of a material. However, the contrast ratio (CR) test is a popular method which describes the ratio of the reflectance from an object resting against a black background to the reflectance obtained against a white background for the same material [9]. The black and white background colors were used in this study because they have been commonly used to assess the translucency and calculate the contrast ratio of various materials [14]. Gehrke and colleagues [28], found that the spectrophotometric shade determination was more reproducible than visual or colorimetric methods. Measuring the effect of the material thickness on the translucency revealed that the thickness significantly affected the translucency of all materials; the greater the thickness, the lower the translucency. This is in accordance with the literature, with respect to how the thickness affects porcelain translucency [2, 9, 26, 27], and is clearly observed in the large thicknesses of $1,1.5$, and $2 \mathrm{~mm}$.

The present study revealed a significant effect of the material type on the translucency of the prosthesis, which is clearly demonstrated with the larger thickness $(1,1.5$, and $2 \mathrm{~mm}$ ) of all materials, except between e.max and Suprinity at 1-mm thickness, and between E-max and Enamic for the 1.5-mm thickness. This translucency variation is in agreement with previous studies [24, 27]. It also shows that, in general, glass-type materials (E-max and Enamic) have greater translucency than zirconiaincorporated materials (Suprinity) which is consistent with the previous studies $[9,26]$.
Translucency can be a disadvantage in certain case scenarios, depending on the clinical situation, e.g., having a discolored tooth or a cast-metal post and core in the anterior esthetic zone, which requires a prosthesis with higher masking abilities and less translucency. This is why it is important to have a complete knowledge of the translucency of different ceramic systems. Many studies have proven that the translucency is affected by the type and thickness of the material $[25,29]$. According to Johnston and Kao [29] evaluating the translucency of IPS Empress 2, In-Ceram Alumina, and Vita Mark II with various core build-up shades found that the final color of an all-ceramic prosthesis is significantly influenced by the color of underlying core composite.

Another study done by Chu et al. [24], comparing the contrast ratios (CR) and color stability of three types of porcelain veneer (Vitadur Alpha, Procera, and Empress 2), found significant differences in the CR. Vitadur Alpha was found to be the most translucent material, but had a weak masking ability. Procera and Empress 2 exhibited higher CR and increased color changes; however, their clinical application may still be limited when a tooth has intense discoloration.

Based on the results obtained from this study, the null hypothesis was rejected, inferring that there were significant differences in translucency between the different thicknesses of zirconia-reinforced lithium silicate, lithium disilicate, and hybrid ceramic when tested against different backgrounds. It is worth mentioning that the current study was conducted in a controlled laboratory setting, where the effect of different light sources on the translucency of the different CAD/CAM ceramic materials was not evaluated. Future studies should be directed towards evaluating the effects of other variables on the translucency of dental ceramics, including, but not limited to the cement shade, finishing technique, light sources, and other environmental conditions that might affect the contrast ratio.

\section{CONCLUSIONS}

Within the limitations of this study, it was observed that the translucency was greatly affected by the thickness of the material; generally, thicker materials were less translucent. Overall, zirconia-reinforced lithium silicate (Suprinity) had the highest contrast ratios, compared to the other materials.

\section{Acknowledgement}

The authors would like to thank the College of Dentistry Research Center and Deanship of Scientific Research at King Saud University, Saudi Arabia, for funding this research project (\#IR 0184). 


\section{REFERENCES}

1. Awad D., Stawarczyk B., Liebermann A., Ilie N. (2017): Translucency of esthetic dental restorative CAD/CAM materials and composite resins with respect to thickness and surface roughness. Journal of Prosthetic Dentistry, 113, 534-540. doi: 10.1016/j.prosdent.2014.12.003

2. Ahn J-S., Lee Y-K. (2017): Difference in the translucency of all-ceramics by the illuminant. Dental Materials, 24, 1539-1544. doi:10.1016/j.dental.2008.03.020

3. Heffernan M.J., Aquilino S.A., Diaz-Arnold A.M., Haselton D.R., Stanford C.M., Vargas M.A. (2017): Relative translucency of six all-ceramic systems. Part I: Core materials. Journal of Prosthetic Dentistry, 88, 4-9. doi: 10.1067/mpr.2002.126794

4. Kursoglu P., Karagoz Motro P.F., Kazazoglu E. (2017): Translucency of ceramic material in different core-veneer combinations. Journal of Prosthetic Dentistry, 113, 48-53. doi: 10.1016/j.prosdent.2014.07.011

5. Lim H.N., Yu B., Lee Y.K. (2010): Spectroradiometric and spectrophotometric translucency of ceramic materials. Journal of Prosthetic Dentistry, 104, 239-246. doi: 10.1016/ S0022-3913(10)60131-X

6. Jeong I-D., Bae S-Y., Kim D-Y., Kim J.H., Kim W.C. (2017): Translucency of zirconia-based pressable ceramics with different core and veneer thicknesses. Journal of Prosthetic Dentistry, 115, 768-772. doi: 10.1016/j.prosdent. 2015.11.003

7. Lee Y.K. (2015): Translucency of dental ceramic, post and bracket. Materials (Basel), 8, 7241-7249. doi: 10.3390/ ma8115379

8. Barizon K.T.L., Bergeron C., Vargas M.A., Qian F., Cobb D.S. Gratton D.G. Geraldeli S. (2017): Ceramic materials for porcelain veneers: Part II. Effect of material, shade, and thickness on translucency. Journal of Prosthetic Dentistry, 112, 864-870. doi:10.1016/j.prosdent.2014.05.016

9. Wang F., Takahashi H., Iwasaki N. (2013): Translucency of dental ceramics with different thicknesses. Journal of Prosthetic Dentistry, 110, 14-20. doi: 10.1016/S0022-3913 (13)60333-9

10. Al-Ben Ali A., Kang K., Finkelman M.D, Zandparsa R., Hirayama H. (2017): The effect of variations in translucency and background on color differences in CAD/CAM lithium disilicate glass ceramics. Journal of Prosthodontics, 23, 213-220. doi: 10.1111/jopr.12080

11. Kurtulmus-Yilmaz S., Ulusoy M. (2014): Comparison of the translucency of shaded zirconia all-ceramic systems. Journal of Advanced Prosthodontics, 6, 415-422. doi: 10.4047/jap.2014.6.5.415

12. Kurklu D., Azer SS., Yilmaz B., Johnston W.M. (2013): Porcelain thickness and cement shade effects on the colour and translucency of porcelain veneering materials. Journal of Dentistry, 41, 1043-1050. doi: 10.1016/j.jdent.2013.08. 017

13. Akar G.C., Pekkan G., Cal E., Eskitaşçığlu G., Özcan M. (2014): Effects of surface-finishing protocols on the roughness, color change, and translucency of different ceramic systems. Journal of Prosthetic Dentistry, 112, 314-321. doi: 10.1016/j.prosdent.2013.09.033

14. Baldissara P., Llukacej A., Ciocca L., Valandro., F.L., Scotti R. (2010): Translucency of zirconia copings made with different CAD/CAM systems. Journal of Prosthetic Dentistry, 104, 6-12. doi: 10.1016/S0022-3913(10)60086-8

15. Succaria F., Morgano S.M. (2011): Prescribing a dental ceramic material: Zirconia vs. lithium-disilicate. Saudi Dental Journal, 23, 165-166. doi: 10.1016/j.sdentj.2011.10.001

16. Vita (2013): Vita Enamic Working Instructions.

17. Peampring C. (2014): Restorative management using hybrid ceramic of a patient with severe tooth erosion from swimming: A clinical report. Journal of Advanced Prosthodontics, 6, 423-426. doi: 10.4047/jap.2014.6.5.423

18. Pop-Ciutrila I-S., Dudea D., Eugenia Badea M., Moldovan M., Cîmpean S.I., Ghinea R. (2016): Shade Correspondence, Color, and Translucency Differences between Human Dentine and a CAD/CAM Hybrid Ceramic System. Journal of Esthetic and Restorative Dentistry, 28, S46-55. doi: 10.1111/jerd.12195

19. Elsaka S.E, Elnaghy A.M. (2016): Mechanical properties of zirconia reinforced lithium silicate glass-ceramic. Dental Materials, 32, 908-914. doi: 10.1016/j.dental.2016.03.013

20. Rinke S., Pabel A-K., Rödiger M., Ziebolz D. (2016): Chairside Fabrication of an All-Ceramic Partial Crown Using a Zirconia-Reinforced Lithium Silicate Ceramic. Case Reports in Dentistry, 2016, 1-7. doi: 10.1155/2016/1354186

21. Dirxen C. (2013): Clinical Performance of a New Biomimetic Double Network Material. Open Dentistry Journal, 7, 118-122. doi: 10.2174/1874210620130904003

22. Jurisic S., Jurisic G., Zlataric D.K. (2015): In Vitro Evaluation and Comparison of the Translucency of Two Different All-Ceramic Systems. Acta Stomatologica Croatia, 49,195-203. doi: 10.15644/asc49/3/1

23. Chaiyabutr Y., Kois J.C., Lebeau D., Nunokawa G. (2011): Effect of abutment tooth color, cement color, and ceramic thickness on the resulting optical color of a CAD/CAM glass-ceramic lithium disilicate-reinforced crown. Journal of Prosthetic Dentistry, 105, 83-90. doi: 10.1016/S00223913(11)60004-8

24. Chu F.C.S., Chow T.W., Chai J. (2007): Contrast ratios and masking ability of three types of ceramic veneers. Journal of Prosthetic Dentistry, 98, 359-364. doi: 10.1016/S00223913(07)60120-6

25. Li Q., Yu H., Wang Y.N. (2019): Spectrophotometric evaluation of the optical influence of core build-up composites on all-ceramic materials. Dental Materials, 25, 158-165. doi: 10.1016/j.dental.2008.05.008

26. Carrabba M., Keeling A.J., Aziz A., Vichi A., Fabian Fonzar R., Wood D., Ferrari M. (2017): Translucent zirconia in the ceramic scenario for monolithic restorations: A flexural strength and translucency comparison test. Journal of Dentistry, 60, 70-76. doi: 10.1016/j.jdent.2017.03.002

27. Barizon K.T.L. (2011): Relative translucency of ceramic systems for porcelain veneers. Journal of Dentistry, 39, 175-165.

28. Gehrke P., Riekeberg U., Fackler O., Dhom G. (2009): Comparison of in vivo visual, spectrophotometric and colorimetric shade determination of teeth and implantsupported crowns. International Journal of Computerized Dentistry, 12, 247-263.

29. Johnston W.M., Kao E.C. (1989): Assessment of appearance match by visual observation and clinical colorimetry. Journal of Dental Research, 68, 819-822. doi: 10.1177/ 00220345890680051301 